\title{
The relationship of narcissism with tendency to react with anger and hostility: The roles of neuroticism and emotion regulation ability
}

\author{
Anna Z. Czarna ${ }^{1} \cdot$ Marcin Zajenkowski $^{2} \cdot$ Oliwia Maciantowicz $^{2} \cdot$ Kinga Szymaniak $^{2}$ (D) \\ Published online: 8 November 2019 \\ (C) The Author(s) 2019
}

\begin{abstract}
The present study examined the relationship of grandiose and vulnerable narcissism with dispositional anger and hostility. We investigated the roles of neuroticism, emotional intelligence, and gender in this relationship, using a sample of 405 participants. The results indicated that vulnerable narcissism was associated with a higher tendency toward anger and hostility, and that neuroticism accounted for a large part of this association. Poor emotion managing, known as strategic emotion regulation ability, also played a role in hostility related to vulnerable narcissism, especially among men. When emotional stability was controlled for, grandiose narcissism showed links to anger and hostility. We concluded that high neuroticism and poor emotion regulation abilities among vulnerable narcissists contribute to increased anger/hostility, whereas emotional stability likely protects grandiose narcissists against these internal aspects of aggression. The significant relationships between both forms of narcissism with aggression, remaining after neuroticism and emotion regulation were accounted for, suggest that there is another underlying source of this link. Finally, we found that controlling for interindividual differences in neuroticism significantly increased the relationship between vulnerable and grandiose narcissism, suggesting the existence of the common core of narcissism.
\end{abstract}

Keywords Anger · Emotional intelligence · Gender differences · Hostility · Narcissism · Neuroticism · Grandiose narcissism · Vulnerable narcissism

Narcissism is a socially aversive personality trait characterized by a self-centered, self-aggrandizing, dominant, and manipulative interpersonal orientation (Emmons 1987; Paulhus and John 1998; Paulhus and Williams 2002). When frustrated in their efforts to maintain a superior sense of self, narcissists are thought to react with narcissistic rage, an explosive mix of anger and hostility. Some evidence suggests that it is narcissistic vulnerability (but not grandiosity) that drives dispositional, internal aspects of aggression, such as rage, anger, and hostility, fueled by shame-proneness, suspiciousness, dejection, and angry rumination (Krizan and Johar 2015). The present study is an investigation into factors that likely link narcissism with internal aspects of aggressiveness: dispositional anger and hostility. In particular, we have examined neuroticism and deficits in emotional regulation as

Kinga Szymaniak

kinga.szymaniak@psych.uw.edu.pl

1 Institute of Applied Psychology, Jagiellonian University, Łojasiewicza 4, 30-348 Krakow, Poland

2 Faculty of Psychology, University of Warsaw, Stawki, 5/7, 00-183 Warsaw, Poland operationalized by Managing emotions component of ability emotional intelligence that may be responsible for narcissists' uncontrollable outbursts of aggression.

\section{Two Forms of Narcissism}

The term narcissism is most commonly associated with grandiose narcissism. This form of narcissism is considered relatively adaptive from the narcissistic person perspective as it correlates negatively with sadness and dispositional depression, anxiety, and loneliness, while positively with wellbeing (Sedikides et al. 2004). Grandiose narcissism is beneficial for psychological health insofar as it is associated with high self-esteem (Sedikides et al. 2004). It correlates positively with extraversion and negatively with neuroticism and agreeableness (Miller et al. 2011). The results from several studies suggest, however, the existence of another form of narcissism termed vulnerable narcissism, which is rooted in a brittle sense of self, associated with low self-esteem and reflects defensiveness and insecurity. It involves feelings of inadequacy, incompetence, and negative affect (Cain et al. 2008; Campbell and Miller 2011; Miller et al. 2011; Pincus 
and Lukowitsky 2010). While arrogance and open displays of dominance and grandiosity characterize grandiose narcissism, the vulnerable form is described by self-reported feelings of inferiority, depression, depletion, shame-proneness, and high reactivity to evaluative events (Kaufman et al. 2018). Vulnerable narcissists' social behavior is marked by hostility, arrogance, social avoidance, and a lack of empathy (Dickinson and Pincus 2003; Hendin and Cheek 1997). Moreover, vulnerable narcissism has been found to largely overlap with neuroticism (Miller et al. 2018). The entitled self-importance has been suggested as a common feature and the core of narcissism that binds narcissistic grandiosity and vulnerability together (Krizan and Herlache 2018). However, whereas grandiose narcissists confidently act out their desire for grandiose self in interactions with their peers, vulnerable narcissists are socially inhibited and mainly concerned with protection of their fragile egos. These pervasive behavioral patterns represent trait-level description of different expressions of narcissism. Importantly, narcissism has also been studied as a state and the commonalities between these two "styles", forms or facets of trait narcissism are most evident at the state-level of analysis. Individuals who self-report high narcissistic features, in particular high narcissistic vulnerability, exhibit within-person fluctuations in grandiosity and vulnerability (Miller et al. 2017). How frequencies of experiencing particular narcissistic states compound to emerge as a stable trait is currently a hot research topic (Edershile and Wright 2019).

It has also been argued that at the trait-level, the common core of narcissism, an antagonistic interpersonal style that stems from an entitled self-image, finds different phenotypic expressions depending on the levels of approach- and avoidance-related motivation (Miller et al. 2017), neuroticism, and extraversion (Ackerman et al. 2019; Jauk et al. 2017a, b). Our research aims to contribute to this notion by investigating links between two forms of narcissism, emotional intelligence, neuroticism and aggression.

\section{Narcissism and Aggression}

The relationship between narcissism and anger, rage and aggression has been a part of many theories, starting from early psychoanalytic to contemporary theories from socialpersonality psychology (e.g. Alexander 1938; Freud 1932; Jacobson 1964; Krizan and Johar 2015; Saul 1947). Multiple empirical studies have documented these relationships (e.g., Martinez et al. 2008; Okada 2010; Reidy et al. 2008; Twenge and Campbell 2003). While earlier views linked grandiose narcissism with aggression (e.g. Bushman and Baumeister 1998), Krizan and Johar (2015) demonstrated that it was vulnerable (but not grandiose) narcissism that predicted aggressiveness, in particular dispositional hostility and anger, and poorer anger control. They showed that vulnerable (but not grandiose) narcissism amplified reactive and displaced aggression in the face of provocation. Taken together, their findings suggest that narcissistic vulnerability is a key source of narcissistic rage, a mix of anger, hostility, and shame. Is this however the only form and aspect of narcissism related to aggression? So far, there has been no consensus regarding this issue. Other researchers have recently found that grandiose narcissism was related to both proactive and reactive aggression while vulnerable narcissism was related to reactive aggression only (Vize et al. 2019). These authors argue that both vulnerable and grandiose narcissism are related to aggressive behavior and this is due to the antagonistic common core of narcissism which consists of arrogance, distrust, entitlement, exploitativeness, lack of empathy, manipulativeness, reactive anger, and thrill-seeking. This antagonistic core, they postulate, remains the strongest predictor for aggressive and antisocial behavior in a variety of aggression outcomes. Our research aims to help elucidate these controversies.

While the findings of Krizan and Johar (2015) seem to support clinical views of narcissistic aggression that implicate deficient self-esteem as an important driver of aggressive behavior, we argue that there may be more than one route linking narcissism with aggression. First of all, in the present study we focus on high neuroticism and poor emotion regulation as the factors linking vulnerable form of narcissism with aggression. By controlling these factors we intend to additionally answer the question whether there might also be space for other important sources of narcissistic aggression next to these ones (such as antagonism).

It is likely that neuroticism, which largely overlaps with vulnerable narcissism (Miller et al. 2018; Pincus et al. 2009) might be the factor responsible for vulnerable narcissists' aggressive reactions. Neuroticism is a personality trait defined as a general tendency toward negative emotionality and frequent experience of anxiety, depression, frustration (Costa and McCrae 1992) and negative affect (e.g., Goryńska et al. 2015; Watson 2000; Zajenkowski et al. 2012). In a recent study, Maciantowicz and Zajenkowski (2018) found that neuroticism mediates the relationship between vulnerable narcissism and anger. Theory and research consistently link neuroticism with trait anger, hostility, and aggression (e.g., Bettencourt et al. 2006; García-Sancho et al. 2017; Hennig et al. 2005; Martin et al. 2000; Sharpe and Desai 2001), especially with aggression in response to provocation. Neuroticism was found to be the most predictive of two subscales of trait aggressiveness, as measured by Buss and Perry's (1992) Aggression Questionnaire: Anger and Hostility subscales (Sharpe and Desai 2001). Neurotic individuals are ineffective in their attempts to cope with stress and prone to engage in irrational thoughts and hostile rumination (Bettencourt et al. 2006). Likewise, vulnerable narcissism 
has been found to correlate with various aspects of negative emotionality (Miller et al. 2011). It is worth noting that stress and negative affect, regardless of their source, are considered factors that increase the likelihood of aggressive behavior and aggression-related phenomena (Anderson and Bushman 2002).

Another factor that might shed some light on vulnerable narcissists' aggressiveness is associated with difficulties in regulating negative emotions. Below, we argue that poor management of emotions, in particular poor management of anger, manifested in low emotional intelligence, may lead to uncontrollable outbursts of rage in vulnerable narcissists.

\section{Narcissism and Emotional Ability}

Salovey and Mayer (1990) first defined emotional intelligence (EI) as "the ability to monitor one's own and others' feelings and emotions, to discriminate among them and to use this information to guide one's thinking and actions" (p. 189). In this model, perceiving, assimilating, understanding, and managing emotions are measured similarly to cognitive intelligence via performance tests. Generally speaking, these features of EI combine to aid in people's ability to adapt to life's changes and solve emotional problems through the use of both rational and emotional coping skills (Mayer and Geher 1996). A number of studies have highlighted the role of emotional abilities in aggressive behavior (Denson 2013; Denson et al. 2011; García-Sancho et al. 2017, 2014). Emotional intelligence may have a crucial role during information processing in social situation (Lemerise and Arsenio 2000). It is necessary for efficient coping and regulation of own and others' emotions, including anger. For instance, deficits in recognition of facial expressions of emotions may result in attributing anger and hostile intent to others in ambiguous situations, and lead to aggressive reactions (see García-Sancho et al. 2014). A crucial component of EI is the ability to strategically regulate emotions in the self and in others, called managing emotions (Lopes et al. 2011). Individuals who are unable to manage strong emotions may be overwhelmed by them during appraisal and decision-making processes, and generate a smaller range of responses, most of which are related to their affective state (e.g., aggressive responses when angry; Lemerise and Arsenio 2000). This perspective suggests that deficits in EI may play a role in aggressive behavior. It is not surprising that EI has been linked to informant reports of positive interpersonal relations. Highly emotionally intelligent individuals are perceived as less aggressive, more prosocial, and more effective than people with low EI (Brackett and Mayer 2003; Mayer et al. 2003; Rice 1999; Rubin 1999).

Grandiose narcissism has been found to be essentially unrelated to deficits of ability EI (e.g., Czarna et al. 2016a, 2016b; Jauk et al. 2016a, b; Konrath et al. 2014), and even to have a positive association with EI measured via self-report methods (trait EI; Austin et al. 2014; Petrides et al. 2011; Vonk et al. 2013; Zajenkowski et al. 2018; Zhang et al. 2015a, b). Additionally, grandiose narcissism shows a negative association with emotion dysregulation, a construct closely related to EI (Zhang et al. 2015a, 2015b; Zeigler-Hill and Vonk 2015). In contrast, vulnerable narcissism may be linked to low emotional ability and difficulties in emotion regulation. Researchers have found that vulnerable narcissism negatively correlates with some EI subfactors (i.e., facilitation and managing emotions; Zajenkowski et al. 2018). Moreover, vulnerable narcissism has been linked to maladaptive emotion regulation, such as nonacceptance of one's own emotional responses, impulse control difficulties, limited access to emotion regulation strategies, and a lack of emotional clarity (Czarna et al. 2018; Miller et al. 2010; Petrides et al. 2011; Zhang et al. 2015a, b). Additionally, vulnerable narcissism has shown substantial similarities in nomological networks of correlates with borderline personality disorder, likely due to similar affective dysregulation and the fact that shame and guilt play a primary role in both (e.g., Hendin and Cheek 1997; Pincus et al. 2009; Rusch et al. 2007; Miller et al. 2010).

\section{The Role of Gender}

There are gender differences in the levels of a majority of variables included in the present study. Men have higher levels of grandiose narcissism (Grijalva et al. 2015; Hartung and Widiger 1998; Stinson et al. 2008), hostility, and aggression, except for the anger facet (Bettencourt and Miller 1996; Buss and Perry 1992). Women have higher levels of contingent self-esteem (Pincus et al. 2009) and neuroticism (Schmitt et al. 2008). Taken together, this suggests that individuals with high levels of vulnerable narcissism might slightly more likely be women, however there has been little empirical research so far in gender differences in vulnerable narcissism (Grijalva et al. 2015). Women also have higher EI (Goldenberg et al. 2006; Harrod and Scheer 2005; Mandell and Pherwani 2003; Mayer et al. 1999; Petrides and Furnham 2000; Schutte et al. 1998; Van Rooy et al. 2005), yet, importantly, some studies suggest that EI is related more strongly to social adjustment for men than it is for women (e.g. Brackett et al. 2004). Furthermore, there is evidence for gender differences in correlates of aggression, and gender-specific relationships and mechanisms that link aggression with personality traits (e.g., Binti Amad 2015; Buss and Perry 1992), including links between aggression and narcissism (Ryan et al. 2008), and neuropsychological correlates of EI (Jaušovec and Jaušovec 2005), and narcissism (Edelstein et al. 2010; Reinhard et al. 2012). Gender was found to be a suppressor and moderator of the effects of self-esteem and narcissism on aggression (Webster 2006) and EI (Jauk et al. 2016a, 2016b). Recent 
empirical evidence (e.g., Jauk et al. 2017a, b) tends to confirm the long hypothesized qualitative difference in expression of narcissism between men and women, with men displaying more emotionally dysfunctional characteristics (Morf and Rhodewalt 2001). Given established gender differences in all the above-mentioned variables and some relevant mechanisms, we found it necessary to examine gender differences and gender-specific mechanisms in our study. In particular, we investigated whether gender moderated relationships between narcissism and anger, and hostility.

\section{The Present Study}

In the present study we examined the relationship of vulnerable and grandiose forms of narcissism with dispositional anger and hostility. The latter two are regarded as internal aspects of aggression (Buss and Perry 1992) and constitute the core of narcissistic rage (Krizan and Johar 2015). We also measured neuroticism and EI, including its components as potential mediators of the narcissism - aggressiveness relationship. We hypothesized that at zero-level vulnerable narcissism, but not grandiose narcissism, would be related to anger and hostility. Furthermore, we expected to find that high neuroticism and low EI would play a role in these relationships.

In the case of neuroticism we expected that this personality trait would have different effect for grandiose and vulnerable narcissism and their relation to anger/hostility. As was mentioned above, recent studies show that vulnerable narcissism overlaps with neuroticism to a high degree and that neuroticism is well suited to differentiate narcissistic grandiosity and vulnerability (e.g. Miller et al. 2018). It has been suggested that frequent experience of negative emotionality, associated with neuroticism, might underlie vulnerable narcissists' tendency toward anger (Maciantowicz and Zajenkowski 2018). Thus, we expected that neuroticism would partially or fully account for the link between vulnerable narcissism and anger/ hostility. In contrast, grandiose narcissism is typically weakly negatively correlated with neuroticism (e.g. Miller et al. 2011). Therefore, our next prediction was that (low) neuroticism might mask the relationship between grandiose narcissism and anger and hostility, and thus, controlling for it, would reveal a positive link between this form of narcissism and anger and hostility (the link likely driven by an antagonistic component of narcissism). We found it plausible that different mediating paths might be significant for different genders and we accounted for this possibility in our study.

Finally, following earlier research (Jauk et al. 2017a, b), we hypothesized that after variance related to neuroticism had been removed from vulnerable and grandiose narcissism, the two forms of this trait would show a significantly higher correlation than the zero-order correlation between the original indices, representing an approximation of the "common core" of narcissism.

\section{Method}

\section{Participants}

Four hundred and six people ${ }^{1}$ (219 women, 187 men) volunteered to participate in the present study. One participant failed to complete all measures and was subsequently excluded from analyses, making the sample 405 participants (218 women, $187 \mathrm{men}$ ). Participants responded to an advertisement posted on the publicly accessible social networking websites and participated at five different sites $^{2}$ (located in two different cities). In exchange for the participation all subjects were offered a financial reward of approximately $10 €$. The sample consisted mainly of undergraduate students and individuals with a Master's degree. Possible differences resulting from different sites of collection were accounted for in the analyses. The mean age of participants was $25.42(S D=6.64)$ with a range of 18 to 57 . Each subject was tested individually in a laboratory at the University of Warsaw or Jagiellonian University. The study was reviewed and approved by the Ethics Committee of the Faculty of Psychology at the University of Warsaw and Bioethics Committee at Jagiellonian University. Written informed consent was obtained from participants at Jagiellonian University. Individuals who took part in the study at the University of Warsaw gave oral informed consent. These two consent obtaining procedures - written and oral - were approved by the respective ethics committees of the two universities. All subjects were allowed to reject or withdraw their participation at any time and without giving any reason.

\section{Measures}

In the current research we were interested in two forms of trait narcissism, i.e. grandiose and vulnerable. Recent review of the measures of narcissism indicate that trait narcissistic grandiosity is best captured by Narcissistic Personality Inventory, whereas trait narcissistic vulnerability is best captured by Hypersensitive Narcissism Scale (Krizan and Herlache 2018). Therefore, we used these measures in our study.

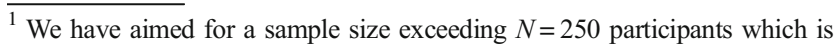
sufficient for detecting average effect sizes in personality psychology with a reasonable likelihood (Schönbrodt and Perugini 2013).

${ }^{2}$ At site 1, data from 71 men were collected $\left(M_{\text {agel }}=23.20, S D_{\text {agel }}=2.24\right)$. At site 2, data from 15 women and 2 men were collected $\left(M_{\text {age2 }}=22.88, S D_{\text {age2 }}=\right.$ $2.50)$. At site 3, data from 44 women and 19 men were collected $\left(M_{\text {age } 3}=\right.$ 22.97, $S D_{\text {age3 }}=3.65$ ). At site 4, data from 94 women and 41 men were collected $\left(M_{\text {age4 }}=27.04, S D_{\text {age } 4}=7.36\right)$. At site 5 , data from 66 women and 54 men were collected $\left(M_{\text {age } 5}=26.49, S D_{\text {age5 }}=8.18\right)$.
} 
Grandiose Narcissism Grandiose narcissism was assessed using the validated Polish adaptation (Bazińska and DratRuszczak 2000) of the Narcissistic Personality Inventory (NPI; Raskin and Hall 1979). The scale is composed of 34 items (e.g., "I like to be the center of attention", "I like to be complimented.") with a 5-point response format ( $1=$ does not apply to me; 5 applies to me). In the current study, $\alpha=.91$.

Vulnerable Narcissism Vulnerable narcissism was assessed using the Polish version (see Czarna et al. 2014) of the Hypersensitive Narcissism Scale (HSNS; Hendin and Cheek 1997). This is a self-report scale that includes 10 items (e.g. "I dislike sharing the credit of an achievement with others", "My feelings are easily hurt by ridicule or the slighting remarks of others.") with a 5-point Likert-like response format (1 = strongly disagree; $5=$ strongly agree). The Polish version, similarly to the original version, correlates negatively with self-esteem. In the current study, $\alpha=.66$.

Neuroticism At sites 2-5, the Polish adaptation (Strus et al. 2014) of the 50-item set of the International Personality Items Pool Big Five Factor Markers questionnaire (Goldberg 1992) was used to assess neuroticism. This measure has a 5-point Likert-type response format ( $1=$ very inaccurate; $5=$ very accurate) and good reliability and validity. In the current study, Cronbach's alpha was .71. The exemplary items are "I get stressed out easily", "I have frequent mood swings". At site 1, the Ten-Item Personality Inventory (Gosling et al. 2003), translated into Polish for the purpose of this study, was used. This scale uses two items ("anxious, easily upset" and "calm, emotionally stable") for each of the five dimensions. Each item is rated on a 7-point scale ( $1=$ disagree strongly; 7 =agree strongly). Because TIPI consists of only two items, internal consistency is not considered an adequate indicator of its reliability, however high stability of the measure was demonstrated in previous studies (Gosling et al. 2003). The scores based on each assessment method were standardized within the subsample using the same method and standardized again within the entire sample to enable comparison across participants. Neuroticism is thus reported as $Z$-scored $(M=0, S D=1)$ in all analyses.

Anger and Hostility Trait anger and hostility were measured using the Aggression Questionnaire (AQ; Buss and Perry 1992). The Anger subscale is composed of 7 items and the Hostility subscale is composed of 8 items, both with a 5-point response format (from 1 - extremely uncharacteristic of me to 5 - extremely characteristic of me). In the present sample, both subscales had good reliability: $\alpha=.74$ (Anger subscale) and $\alpha=.78$ (Hostility subscale). The exemplary items for Anger and Hostility subscale are "Some of my friends think I am hothead", "I sometimes feel like a powder keg ready to explore" and "I am suspicious of overly friendly strangers", "At times I feel I have gotten a raw deal out of life".

Ability Emotional Intelligence Ability EI was measured with The Test of Emotional Intelligence (Śmieja et al. 2014). It is based on Salovey and Mayer 1990; Mayer and Salovey 1997) concept of EI. The scale consists of 24 items and four subscales which represent a fairly diverse domain of abilities: Perception (measuring aptitude to accurately perceive emotions in oneself and others as well as in objects, art, stories, music, and other stimuli), Understanding (measuring the ability to understand emotional information, to understand how emotions combine and progress through relationship transitions, and to appreciate such emotional meanings), Facilitation (measuring ability to generate and integrate emotion as necessary to communicate feelings or to facilitate thought), and Managing emotions (measuring ability to be open to feelings, and to modulate, regulate them strategically in oneself and others so as to promote personal understanding and growth). Participants are provided with descriptions of social situations and asked to indicate on a 5-point Likert-scale (1 to 5) the emotions involved in a given situation, or to suggest the most appropriate action. Standard scoring algorithm for the test has been developed based on the similarity of the participants' answers and responses administered by a group of experts (professional psychotherapists, HR specialists, and coaches) during the validation process. The points are summed up separately for all subscales and for the whole measure. Reliability and validity of the test were assessed in multiple studies (Śmieja et al. 2014). The reliability of the total score equals $\alpha=.88$, and internal consistency for each subscale equals .70, .69, .65, .66 for Perception, Understanding, Facilitation and Managing respectively. An exemplary item for The Test of Emotional Intelligence is:

Sophie hits the table with a fist. She frowns, her face is glowing, and her teeth are clenched. Most probably:

(a) She is watching a popular show on TV

$1 \ldots \ldots . . \ldots . .3 \ldots . . . . . .5$

(b) Once again she hurt her finger while cutting bread

$1 \ldots \ldots . . \ldots . .3 \ldots . . . . . .5$

(c) She was just told by a colleague that he will not help her to prepare an important project, because he is leaving for a last-minute holiday

$1 \ldots \ldots . . \ldots . . . . . .4 \ldots \ldots .5$ 
Table 1 Correlations and descriptive statistics for all variables

\begin{tabular}{|c|c|c|c|c|c|c|c|c|c|c|}
\hline & 1 & 2 & 3 & 4 & 5 & 6 & 7 & 8 & 9 & 10 \\
\hline 1.HSNS & - & .06 & $.41^{* *}$ & .08 & .06 & $-.16^{* * *}$ & -.04 & -.01 & $.30^{* *}$ & $.48^{* * *}$ \\
\hline 2.NPI & & - & $-.22^{* *}$ & -.02 & .04 & .04 & -.05 & .01 & .04 & .02 \\
\hline 3.Neuroticism & & & - & .10 & $.13^{* *}$ & -.08 & .06 & .07 & $.48^{* *}$ & $.43^{* *}$ \\
\hline 4.EI Perception & & & & - & $.62^{* *}$ & $.50^{* *}$ & $.45^{* *}$ & $.83^{* *}$ & .03 & -.04 \\
\hline 5.EI Understanding & & & & & - & $.51^{* *}$ & $.43^{* *}$ & $.82^{* * *}$ & .08 & .03 \\
\hline 6.EI Facilitation & & & & & & - & $.43^{* * *}$ & $.77^{* * *}$ & -.05 & $-.18^{* *}$ \\
\hline 7.EI Management & & & & & & & - & $.71^{* *}$ & -.03 & $-.14^{* *}$ \\
\hline 8. EI Total & & & & & & & & - & .02 & -.10 \\
\hline 9.Anger & & & & & & & & & - & $.38^{* *}$ \\
\hline 10.Hostility & & & & & & & & & & - \\
\hline$M$ & 29.90 & 103.54 & 0.00 & 7.95 & 7.55 & 7.17 & 6.46 & 29.13 & 19.62 & 21.75 \\
\hline$S D$ & 5.71 & 18.66 & 1.00 & 1.59 & 1.50 & 1.43 & 1.30 & 4.58 & 6.09 & 6.20 \\
\hline
\end{tabular}

$N=406{ }^{* *} p<.01$ (two-tailed)

\section{Results}

\section{Correlations and Descriptive Statistics}

In Table 1 we present descriptive statistics and correlations for the entire sample. It needs to be acknowledged that the reliability coefficient for the HSNS (vulnerable narcissism) was relatively low $(\alpha=.66)$. However, both in the original research (Hendin and Cheek 1997) and in other studies using the Polish translation of the measure (e.g., Czarna et al. 2014; Czarna et al. 2016a, b; Maciantowicz and Zajenkowski 2018; Rogoza et al. 2018; Zajenkowski et al. 2016), the alpha coefficient oscillates around .70 (ranging from .62 to .75). Nevertheless, the results associated with this scale should be taken with caution.

Subsequently, we calculated gender differences between variables (see Table 2) and found significant (or marginal) differences in levels of all variables in our study except for the HSNS scores. Women were significantly higher in neuroticism (lower emotional stability) and all individual aspects and the total score of EI (the difference in facilitation was marginal), but also higher in the scales of anger and hostility. Men had significantly higher NPI scores. We then ran correlations between the variables in the study within gender groups (see Table 3 ).

In the entire sample and within gender groups, we found that HSNS and NPI had relationships of opposite direction with neuroticism: HSNS correlated positively with neuroticism and NPI did negatively. In the entire sample, HSNS correlated negatively with the facilitation subscale of EI and no other links between narcissism of any form and EI were detected. This correlation was driven by the correlation in the female subsample. However, among men, the correlation with facilitation was not significant and instead poor managing emotions was significantly related to HSNS. Furthermore, while in both gender groups, and the whole sample, HSNS correlated significantly and moderately positively with anger and hostility, there was a positive correlation between NPI and hostility only among women. Finally, among both men and women, neuroticism correlated significantly positively with anger and hostility and the facilitation aspect of EI correlated negatively with hostility in both men and women. Exclusively among men, poor managing emotions was a significant correlate of anger and hostility.

\section{Predictors of Anger and Hostility}

We then tested whether the relationships between HSNS and NPI and anger and hostility could be explained by differences in neuroticism and/or EI that are systematically related to narcissism. We used a conservative approach to these tests and only selected the variables that showed zero-order correlations with both predictor and outcome variables. Thus, we tested whether neuroticism, facilitation, and managing emotions could in part or fully explain the relationship between narcissism (HSNS and NPI) and anger and, separately, hostility.

First, we ran a hierarchical regression of anger (see Table 4). In the first step, we entered HSNS and NPI as well as gender and the interaction terms of narcissism (each form) with gender. In this step we also controlled for site-ofcollection differences: they were accounted for with four dummy-coded variables with the largest group, site 1 , used as the reference group.. ${ }^{3}$ In the second step, we entered neuroticism, facilitation and managing emotions. In the third step, we added an interaction effect of managing emotions and

\footnotetext{
${ }^{3}$ We found the following site-of-collection differences: site 4 was significantly lower in anger than site 1 and site 5 was significantly higher in hostility than site 1 . The site differences did not change the results: the described effects held regardless of whether the analyses controlled for the site differences or not.
} 
Table 2 Gender differences in the levels of all variables

\begin{tabular}{lllllllll}
\hline & $M_{f}$ & $S D_{f}$ & $M_{M}$ & $S D_{f}$ & $t$ & $d f$ & $p$ & Cohen's $d$ \\
\hline 1. HSNS & 30.16 & 5.71 & 29.60 & 5.7242 & .98 & 403 & .329 & .10 \\
2. NPI & 100.28 & 18.48 & 107.35 & 18.20 & -3.87 & 403 & $<.001$ & .39 \\
3. Neuroticism & .28 & .90 & -.33 & 1.01 & 6.36 & 403 & $<.001$ & .63 \\
4. EI Perception & 8.09 & 1.64 & 7.78 & 1.51 & 1.92 & 404 & .056 & .19 \\
5. EI Understanding & 7.77 & 1.47 & 7.29 & 1.49 & 3.22 & 404 & .001 & .32 \\
6. EI Facilitation & 7.35 & 1.40 & 6.95 & 1.44 & 2.83 & 404 & .005 & .28 \\
7. EI Management & 6.82 & 1.15 & 6.05 & 1.35 & 6.08 & $367.94^{\mathrm{a}}$ & $<.001$ & .61 \\
8. EI Total & 30.02 & 4.55 & 28.08 & 4.41 & 4.35 & 404 & $<.001$ & .43 \\
9. Anger & 20.86 & 6.17 & 18.18 & 5.68 & 4.51 & 404 & $<.001$ & .45 \\
10. Hostility & 22.43 & 6.47 & 20.95 & 5.79 & 2.42 & 404 & .016 & .24 \\
\hline
\end{tabular}

In the case of EI Management, we reported the result of $t$-test without the assumption of homogeneity of variances because Levene's test of homogeneity of variances yielded a significant result, indicating that the variances in the two subgroups are significantly different gender, as correlations indicated that there might be a gender difference in links between this subscale of EI and anger. The results showed that in the first step HSNS and gender significantly predicted anger (men reported less anger than women). Neither the NPI nor any of the interaction terms were significant (neither HSNS with gender, nor NPI with gender). Results of the second step showed that neuroticism and managing emotions significantly predicted anger while facilitation did not. Furthermore, now both forms of narcissism were also significant predictors of anger: the strength of HSNS as a predictor decreased while NPI emerged to full significance . An interaction effect of managing emotions and gender entered in the third step was not significant and thus dropped. The entire model explained around $30 \%$ of variance of the dependent variable $\left(\right.$ Adj. $\left.R^{2}=.30, F[12,392)\right]=10.71$, $p<.001)$. Importantly, predictors entered in the first step accounted for $14.6 \%$ of that variance and the ones entered in the second step improved prediction by $15.4 \%$ : neuroticism explained $14.7 \%$ of variance and managing emotions less than $1 \%$.
Next, we conducted an analogous hierarchical regression of hostility (see Table 5) The setup and the order of variables entered was identical. The results of the first step showed that narcissism of each form was significantly related to hostility (significant main effect of HSNS and the interaction of HSNS with gender, as well as the interaction of NPI with gender). Simple slope analyses showed that HSNS predicted hostility more strongly among women than men (among women: $b=.57, t=9.55, p<.001$, among men: $b=.39, t=5.95$, $p<.001$ ), while NPI had marginal relationships of opposite directions among women and men (among women: $b=.10$, $t=1.67, p=.096$, among men: $b=-.11, t=-1.74, p=.083$ ). Results of the second step showed that neuroticism and managing emotions significantly predicted hostility while facilitation did not. Furthermore, effects of narcissism were significant (main effect of HSNS and the interaction of HSNS with gender, as well as the interaction of NPI with gender). Simple slope analyses showed that HSNS predicted hostility more strongly among women than men (among women: $b=.44$, $t=7.29, p<.001$, among men: $b=.25, t=3.83, p<.001)$

Table 3 Correlations for all variables among women (above the diagonal) and among men (below the diagonal)

\begin{tabular}{|c|c|c|c|c|c|c|c|c|c|c|}
\hline & 1 & 2 & 3 & 4 & 5 & 6 & 7 & 8 & 9 & 10 \\
\hline 1. HSNS & - & .09 & $.45^{* *}$ & .05 & .00 & $-.20^{* *}$ & .05 & -.03 & $.37^{* *}$ & $.55^{* *}$ \\
\hline 2. NPI & .05 & - & $-.14^{*}$ & .03 & .05 & .00 & .02 & .03 & .12 & $.15^{*}$ \\
\hline 3. Neuroticism & $.38^{* *}$ & $-.21^{* *}$ & - & .08 & .04 & -.09 & .06 & .03 & $.51^{* *}$ & $.37^{* *}$ \\
\hline 4. EI Perception & .11 & -.03 & .07 & - & $.66^{* *}$ & $.51^{* *}$ & $.48^{* *}$ & $.86^{* *}$ & .03 & -.05 \\
\hline 5. EI Understanding & .13 & .08 & .14 & $.55^{* * *}$ & - & $.53^{* *}$ & $.51^{* *}$ & $.85^{* *}$ & .03 & -.02 \\
\hline 6. EI Facilitation & -.13 & .14 & $-.16^{*}$ & $.47^{* *}$ & $.48^{* *}$ & - & $.39^{* *}$ & $.76^{* *}$ & -.09 & $-.20^{* *}$ \\
\hline 7. EI Management & $-.16^{*}$ & .00 & -.11 & $.40^{* * *}$ & $.31^{* *}$ & $.42^{* *}$ & - & $.71^{* *}$ & -.01 & -.13 \\
\hline 8. EI Total & -.01 & .06 & -.01 & $.80^{* * *}$ & $.78^{* *}$ & $.78^{* * *}$ & $.68^{* *}$ & - & -.01 & -.12 \\
\hline 9. Anger & $.21^{* *}$ & .05 & $.39^{* * *}$ & -.03 & .06 & -.07 & $-.18^{*}$ & -.07 & - & $.37^{* *}$ \\
\hline 10. Hostility & $.38^{* * *}$ & -.10 & $.46^{* *}$ & -.06 & .05 & $-.20^{* * *}$ & $-.23^{* *}$ & -.14 & $.36^{* *}$ & - \\
\hline
\end{tabular}

$N_{\text {women }}=218 . N_{\text {men }}=187 .{ }^{*} p<.05,{ }^{* *} p<.01$ (two-tailed) 
Table 4 Hierarchical regression of anger

Dependent variable: anger

\begin{tabular}{lllll}
\hline \multirow{5}{*}{ Step 1 } & Predictors & $\beta$ & $t$ & $p$ \\
& Gender & -.16 & -2.91 & .004 \\
& HSNS & .32 & 6.70 & $<.001$ \\
& NPI & .06 & 1.18 & .239 \\
& HSNS x Gender & -.07 & -1.52 & .130 \\
Step 2 & NPI x Gender & -.03 & -.66 & .512 \\
& Gender & -.04 & -.64 & .522 \\
& HSNS & .13 & 2.67 & .008 \\
& NPI & .15 & 3.35 & .001 \\
& HSNS x Gender & -.07 & -1.55 & .121 \\
& Neuroticism & -.02 & -.37 & .710 \\
& Facilitation & .46 & 9.18 & $<.001$ \\
& Managing emotions & .03 & .65 & .515 \\
Gender 3 & -.10 & -2.00 & .046 \\
& HSNS & -.04 & -.66 & .510 \\
& NPI & .13 & 2.62 & .009 \\
& HSNS x Gender & .15 & 3.34 & .001 \\
NPI x Gender & -.07 & -1.58 & .115 \\
Neuroticism & -.02 & -.37 & .715 \\
Facilitation & .46 & 9.13 & $<.001$ \\
Managing emotions & .03 & .63 & .527 \\
Managing emotions x Gender & -.02 & -.54 & .589 \\
\hline
\end{tabular}

At each step dummy-coded site-of-collection differences were also controlled for

though the magnitude of the relationships decreased, while NPI now had a significant positive relationship with hostility among women but not men (among women: $b=.15, t=2.64$, $p=.009$, among men: $b=-.04, t=-.60, p=.549)$. An interaction effect of managing emotions and gender entered in the third step was not significant and thus dropped. The entire model explained around $34 \%$ of variance of the dependent variable $\left(A d j . R^{2}=.34, F[12,392]=12.07, p<.001\right)$. Importantly, predictors entered in the first step accounted for $25.6 \%$ of that variance and the ones entered in the second step improved prediction by $8.5 \%$ : neuroticism explained $5.7 \%$ of variance and managing emotions $2.8 \%$.

\section{Plausible Mediators}

Although our data do not allow for causal inferences, having found changes in the strength of relationships between narcissism (of each form) and anger and hostility after accounting for neuroticism and managing emotions, which might suggest a mediation (or suppression - in the case of NPI), we have formally tested for theoretically plausible mediations. Both candidate mediators were entered together in each model. Again, site-of-collection differences were accounted for with
Table 5 Hierarchical regression of hostility

Dependent variable: hostility

\begin{tabular}{|c|c|c|c|c|}
\hline & Predictors & $\beta$ & $t$ & $p$ \\
\hline \multirow[t]{5}{*}{ Step 1} & Gender & -.07 & -1.29 & .20 \\
\hline & HSNS & .49 & 10.96 & .000 \\
\hline & NPI & .00 & .04 & .972 \\
\hline & HSNS x Gender & -.09 & -2.06 & .040 \\
\hline & NPI x Gender & -.10 & -2.41 & .016 \\
\hline \multirow[t]{8}{*}{ Step 2} & Gender & -.03 & -.58 & .559 \\
\hline & HSNS & .35 & 7.55 & .000 \\
\hline & NPI & .06 & 1.48 & .140 \\
\hline & HSNS x Gender & -.10 & -2.34 & .020 \\
\hline & NPI x Gender & -.09 & -2.25 & .025 \\
\hline & Neuroticism & .28 & 5.81 & .000 \\
\hline & Facilitation & -.03 & .67 & .505 \\
\hline & Managing emotions & -.16 & -3.43 & .00 \\
\hline \multirow[t]{9}{*}{ Step 3} & Gender & -.03 & -.56 & .578 \\
\hline & HSNS & .36 & 7.58 & .000 \\
\hline & NPI & .06 & 1.49 & .138 \\
\hline & HSNS x Gender & -.10 & -2.29 & .022 \\
\hline & NPI x Gender & -.09 & -2.25 & .025 \\
\hline & Neuroticism & .29 & 5.84 & .000 \\
\hline & Facilitation & -.03 & -.64 & .522 \\
\hline & Managing emotions & -.17 & -3.50 & .001 \\
\hline & Managing emotions x Gender & .03 & .75 & .45 \\
\hline
\end{tabular}

At each step dummy-coded site-of-collection differences were also controlled for

four dummy-coded variables which were entered as controls in our analyses. The largest group, site 1, was used as the reference group. ${ }^{3}$ We also controlled for NPI in all analyses where HSNS was an outcome variable (and vice versa). The setup of each analysis was informed by the results of reported correlation and regression analyses as described below.

\section{Mediators of the Links between Vulnerable Narcissism and Anger and Hostility}

Given observed gender differences in the link between HSNS and managing emotions, when testing mediators for anger we first allowed for the paths between predictor and mediator to be moderated by gender. Managing emotions however failed to emerge as a significant mediator between HSNS and anger and was subsequently dropped from the analysis, simplifying the model to non-moderated mediation with a single mediator. Bootstrapped results indicated that the $95 \%$ confidence interval of the indirect effect between HSNS and anger did not contain zero exclusively for neuroticism. The indirect effects were significant among men and among women and there was no significant difference between these conditional indirect effects as indicated by insignificant moderated mediation 
Fig. 1 Mediation of vulnerable narcissism via neuroticism on anger

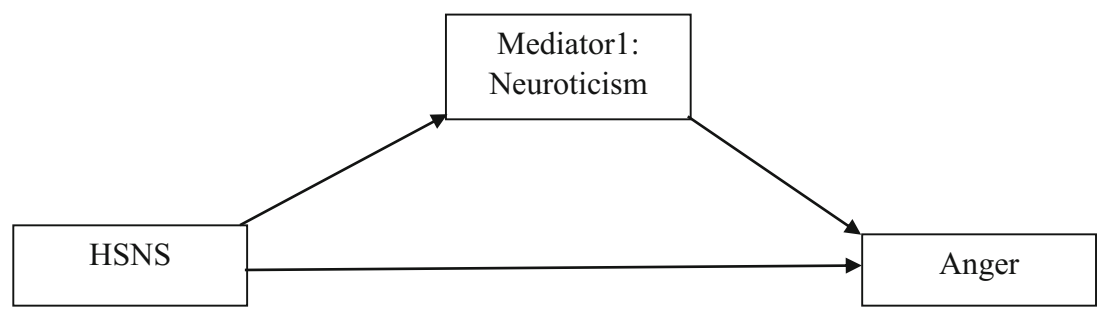

index; we thus calculated confidence intervals for the entire sample [.82, 1.55]. The direct effect remained significant. Thus, neuroticism was a partial mediator of the relationship between HSNS and anger (see Fig. 1, Table 6).

For hostility, we again allowed for the paths between predictor and mediator to be moderated by gender and tested indirect effects in each gender group as well as formally tested the difference between these conditional indirect effects. We also controlled for the interaction between NPI and gender in this analysis. Bootstrapped results indicated that the $95 \%$ confidence interval of the indirect effect between HSNS and hostility did not contain zero for neuroticism among men [.34, 1.10] or among women $[.48,1.15]$, and that a gender difference between these conditional indirect effects was not significant as indicated by an insignificant index of moderated mediation $[-.43, .22]$. Furthermore, bootstrapped results indicated that the $95 \%$ confidence interval of the indirect effect between HSNS and hostility did not contain zero for managing emotions among men only $[.01, .44]$, while it did among women $[-.18, .10]$. An index of moderated mediation for this gender difference was significant $[.01, .51]$ indicating that the conditional indirect effects were significantly different. The direct effects remained significant. Thus, neuroticism was a partial mediator of the relationship between HSNS and hostility among both men and women while managing emotions was an additional partial mediator between relationship of HSNS and hostility only among men (see Fig. 2, Table 7).

Table 6 Results of mediation of vulnerable narcissism via neuroticism on anger

\begin{tabular}{llll}
\hline Mediation Results & Coefficient & LLCI & ULCI \\
\hline Outcome: Neuroticism $\mathrm{R}^{2}=.31, F(7,397)=25.17, p<.001$ & \\
HSNS & $.41^{* *}$ & .33 & .50 \\
Gender & $-.65^{* *}$ & -.84 & -.45 \\
Outcome: Anger $\mathrm{R}^{2}=.31, F(8,396)=22.08$, & $p<.001$ & \\
HSNS & $.78^{* *}$ & .21 & 1.36 \\
Gender & -.05 & -1.31 & 1.21 \\
Neuroticism & $2.83^{* *}$ & 2.23 & 3.43 \\
Direct effect & $.78^{* *}$ & .21 & 1.36 \\
Indirect effect & $1.16^{* *}$ & .82 & 1.55 \\
\hline
\end{tabular}

This analysis also controlled for grandiose narcissism and dummy-coded site-of-collection differences. LLCI: Lower Limit Confidence Interval, ULCI: Upper Limit Confidence Interval. ${ }^{*} p<.05,{ }^{* *} p<.01$

\section{Mediators of the Links between Grandiose Narcissism and Anger and Hostility}

We then tested a simple mediation model between NPI and anger with two candidate mediators: neuroticism and managing emotions entered simultaneously. Bootstrapped $95 \%$ confidence interval of the indirect effect between NPI and anger did not contain zero for neuroticism $[-.88, .-30]$. The direct effect was significant. We found that low neuroticism significantly suppressed the relationship between NPI and anger (Fig. 3, Table 8). Managing emotions failed to significantly mediate the link.

Since we knew that NPI had different links with hostility among men and women, we allowed for the path between predictor and outcome to be moderated by gender, when testing possible mediators of the link. We also controlled for the interaction between HSNS and gender in this analysis ${ }^{4}$. Managing emotions failed to significantly mediate the link and was dropped from the model, thus simplifying it to a single mediator model. The results showed that low neuroticism significantly suppressed the relationship between NPI and hostility among both men and women and that this indirect effect was not significantly different between the two gender subgroups. The direct effect was significant among women. Bootstrapped $95 \%$ confidence interval of the indirect effect between NPI and hostility in the entire sample did not contain zero for neuroticism (among women: $[-.56,-.09]$, among men: $[-.79,-.15]$, in the full sample $[-.71,-.24])$. Thus, only neuroticism emerged as a likely suppressor between NPI and hostility (Fig. 4, Table 9).

\section{The Common Core of Narcissism}

Finally, following Jauk et al. (2017a, b), we have partialled out the variance related to neuroticism from HSNS and NPI, in order to test whether indices created in this way (i.e., residualized) would show a significantly higher correlation than the original indices, HSNS and NPI. The results showed that indeed, the correlation of these residualized indices, $r(405)=.87, p<.001$, was substantially higher than the zero-

\footnotetext{
${ }^{4}$ We have also repeated all mediation analyses without controlling for the counterpart form of narcissism (and its interaction with gender) and the results were essentially the same. Importantly, the significance of all reported indirect and direct effects was unchanged.
} 
Fig. 2 Moderated mediation of vulnerable narcissism via neuroticism and managing emotions on hostility. The dashed line represents an insignificant moderation effect

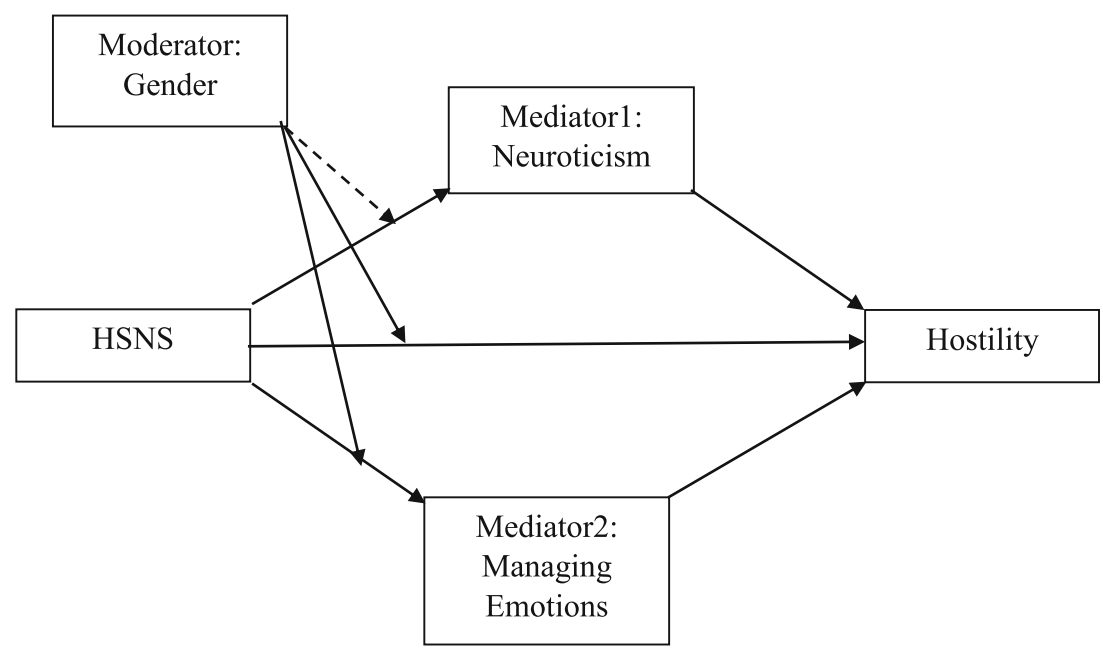

level correlation of the original indices, $r(405)=.06, p=.207$. The difference was significant, $z=18.18, p<.001$.

\section{Discussion}

In the present study, we examined the relationship between grandiose and vulnerable narcissism and two internal aspects of aggression: anger and hostility. The results indicated that vulnerable narcissism, but not grandiose narcissism, was associated with a tendency toward experiencing anger and a hostile attitude. Thus, we have further supported the narcissistic rage concept proposed by Krizan and Johar (2015), who suggested that among the two forms of narcissism, only the vulnerable one is related to chronic anger, distrust, and hostility, which constitute the core aspects of narcissistic rage. We also investigated factors that might potentially explain the vulnerable narcissists' tendency to increased anger and hostility. These analyses revealed interesting results concerning the roles of neuroticism, EI, and gender. We have however also found unmodelled, direct shared variance between narcissism and aggression, suggesting the existence of another possible source of this common variance. Finally, we investigated and confirmed that removing the variance related to neuroticism from the indices of vulnerable and grandiose narcissism would increase the correlation between the two, thus revealing an approximation of the "common core" of narcissism.

First, we confirmed earlier findings showing distinct relationships between vulnerable and grandiose forms of narcissism and neuroticism (Maciantowicz and Zajenkowski 2018; Miller et al. 2018; Pincus et al. 2009; Sedikides et al. 2004). Neuroticism can indeed help differentiate the two forms of narcissism. Vulnerable narcissists were highly neurotic and grandiose narcissists were relatively emotionally stable. Furthermore, neuroticism turned out to be a significant factor in the link between vulnerable narcissism and anger and hostility. These findings corroborate earlier research into neuroticism (Bettencourt et al. 2006). Although our study design does not allow to draw inferences about causality and several alternative pathways are conceivable, we have decided to test and argue that, in line with our hypotheses and some previous evidence (Maciantowicz and Zajenkowski 2018), neuroticism is a likely mediator of the relationship between vulnerable narcissism and both anger and hostility. It is possible that vulnerable narcissists, similarly to neurotics (see Matthews et al. 2009), are more sensitive to stimuli that evoke negative emotions, more reactive to stressors, and less efficient at coping with stress. Thus, overwhelmed by negative affect, vulnerable narcissists may be prone to experiencing increased levels of frustration, anger, dejection, and negative evaluations of self and others (hostility) and shame.

Although vulnerable narcissism did not correlate with the global ability EI, it was significantly associated with low facilitation subscale from the ability EI measure among women - in line with earlier findings (Zajenkowski et al. 2018). This aspect of EI reflects an ability to assimilate emotions with thinking and problem solving as well as to use emotion to direct attention to important information (Mayer et al. 2004). Low facilitation ability might make it difficult for vulnerable narcissists to disengage thoughts from negative emotions, which in turn can lead to biased information processing. This aspect of EI, however, did not play a significant role in the investigated relationships. Instead, another aspect of low EI, poor managing emotions, known also as strategic emotion regulation ability, emerged as a significant factor in the link between vulnerable narcissism and hostility among men. Difficulties in regulating one's own and others' emotions, along with high neuroticism, might be responsible for some of the common problems observed in vulnerable narcissistic men: hostility. However, it is important to acknowledge that EI and neuroticism seem to be independent mediators of the narcissism-hostility relation, which confirms earlier findings about how strategic emotion regulation ability operates (Lopes et al. 2011). Earlier research has already linked lower 
Table 7 Results of moderated mediation of vulnerable narcissism via neuroticism and managing emotions on hostility

\begin{tabular}{|c|c|c|c|}
\hline Moderated Mediation Results & Coefficient & LLCI & ULCI \\
\hline \multicolumn{4}{|c|}{ Outcome: Neuroticism $\mathrm{R}^{2}=.31, F(9,395)=19.71, p<.001$} \\
\hline HSNS & $.41^{* *}$ & .33 & .50 \\
\hline Gender & $-.65^{* *}$ & -.85 & -.45 \\
\hline HSNS x Gender & -.07 & -.24 & .10 \\
\hline \multicolumn{4}{|l|}{ Conditional effects: } \\
\hline Among women & $.44^{* *}$ & .33 & .56 \\
\hline Among men & $.37^{* *}$ & .25 & .50 \\
\hline \multicolumn{4}{|c|}{ Outcome: Managing Emotions $\mathrm{R}^{2}=.11, F(9,395)=5.60, p<.001$} \\
\hline HSNS & -.06 & -.16 & .03 \\
\hline Gender & $-.63^{* *}$ & -.85 & -.41 \\
\hline HSNS x Gender & $-.22^{*}$ & -.41 & -.03 \\
\hline \multicolumn{4}{|l|}{ Conditional effects: } \\
\hline Among women & .04 & -.09 & .17 \\
\hline Among men & $-.18^{*}$ & -.32 & -.04 \\
\hline \multicolumn{4}{|c|}{ Outcome: Hostility $\mathrm{R}^{2}=.36, F(9,395)=19.84, p<.001$} \\
\hline HSNS & $2.22^{* *}$ & 1.65 & 2.78 \\
\hline Gender & -.35 & -1.65 & .94 \\
\hline HSNS x Gender & $-1.24^{*}$ & -2.26 & -.22 \\
\hline Neuroticism & $1.77^{* *}$ & 1.17 & 2.36 \\
\hline Managing Emotions & $-1.08^{* *}$ & -1.61 & -.56 \\
\hline \multicolumn{4}{|l|}{ Direct effects } \\
\hline Among women & $2.79^{* *}$ & 2.06 & 3.52 \\
\hline Among men & $1.55^{* *}$ & .76 & 2.34 \\
\hline \multicolumn{4}{|l|}{ Indirect effect via Neuroticism } \\
\hline Among women & $.78^{* *}$ & .48 & 1.15 \\
\hline Among men & $.66^{* *}$ & .34 & 1.10 \\
\hline \multicolumn{4}{|c|}{ Indirect effect via Managing Emotions } \\
\hline Among women & -.04 & -.18 & .10 \\
\hline Among men & $.20^{*}$ & .01 & .44 \\
\hline
\end{tabular}

This analysis controlled for grandiose narcissism and its interaction with gender, and dummy-coded site-of-collection differences. LLCI: Lower Limit Confidence Interval, ULCI: Upper Limit Confidence Interval. ${ }^{*} p<.05,{ }^{* *} p<.01$

EI in men, with negative outcomes, including illegal drug and alcohol use, deviant behavior, and poor relations with other people (Brackett et al. 2004). Ability to manage emotions has been shown to impact quality of interpersonal relationships, in particular levels of interpersonal conflict (Lopes et al. 2011). It
Table 8 Results of mediation of grandiose narcissism via neuroticism on anger

\begin{tabular}{llll}
\hline Mediation Results & Coefficient & LLCI & ULCI \\
\hline Outcome: Neuroticism $\mathrm{R}^{2}=.31, F(7,397)=25.17, p<.001$ & \\
NPI & $-.20^{* *}$ & -.29 & -.12 \\
Gender & $-.65^{* *}$ & -.84 & -.45 \\
Outcome: Anger $\mathrm{R}^{2}=.31, F(8,396)=22.08$, & $p<.001$ & \\
NPI & $.92^{* *}$ & .39 & 1.44 \\
Gender & -.05 & -1.31 & 1.21 \\
Neuroticism & $2.83^{* *}$ & 2.23 & 3.43 \\
Direct effect & $.92^{* *}$ & .39 & 1.44 \\
Indirect effect & $-.57^{* *}$ & -.88 & -.29 \\
\hline
\end{tabular}

This analysis also controlled for vulnerable narcissism and dummy-coded site-of-collection differences. LLCI: Lower Limit Confidence Interval, ULCI: Upper Limit Confidence Interval. ${ }^{*} p<.05,{ }^{* *} p<.01$

helps people to preempt fruitless conflict or attenuate the negative impact of personal antagonisms more than it helps to enhance the positive dimension of relationship quality, such as social bonding, companionship, nurturance or intimacy. Those findings remained significant even after statistically controlling for scores on the Big Five and academic achievement. EI was significantly associated with maladjustment and negative behaviors for college-aged men, but not for women (Brackett et al. 2004). Moreover, inability to control emotions, and anger in particular, lead to interpersonal problems and social maladjustment especially among men (e.g. Caspi et al. 1987; Brackett et al. 2006).

Interestingly, our findings show that managing emotions plays a role in explaining only hostility but not anger of men with high levels of vulnerable narcissism. The reason for this might lie in the nature of the two facets of aggression. While anger, measured with items such as "I flare up quickly but get over it quickly" or "When frustrated, I let my irritation show", involves physiological arousal and preparation for aggression, represents the emotional or affective component of aggressive behavior, hostility consists of feelings of ill will and injustice, being wronged and disadvantaged, resentment and suspicion of others' motives and represents the cognitive (and internalizing, to a certain degree) component of aggressive behavior (Buss and Perry 1992). Thus hostility might likely constitute an antecedent of the emotional component. Hostility, as
Fig. 3 Mediation of grandiose narcissism via neuroticism on anger

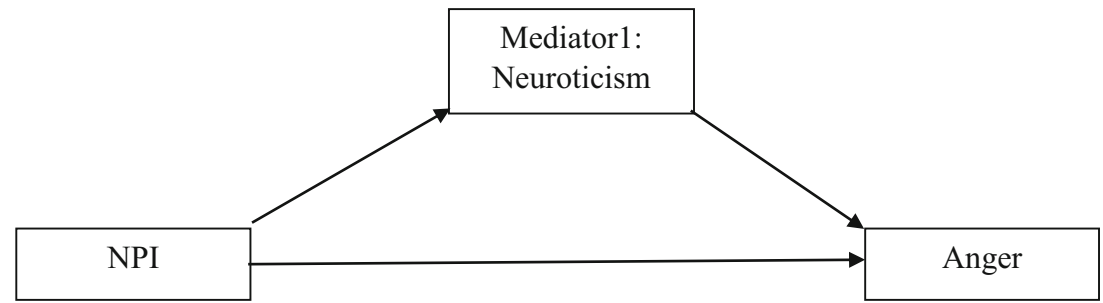


Fig. 4 Moderated mediation of grandiose narcissism via neuroticism on hostility. The dashed line represents an insignificant moderation effect

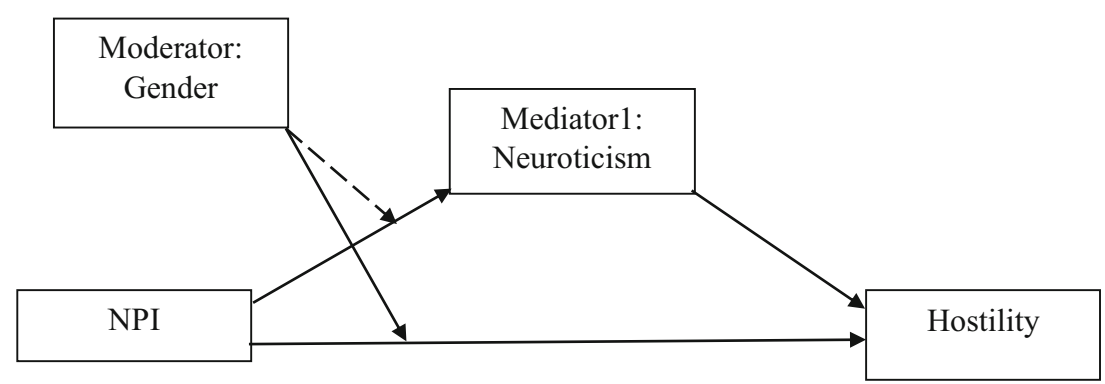

defined by Buss and Perry (1992) and measured with items such as "I am sometimes eaten up with jealousy" or "At times I feel I have gotten a raw deal out of life", is covert, internalizing (unlike anger, which is overt and expressive, externalizing), not easily observable, strongly related to negative emotionality and, importantly, has the strongest links to low selfesteem among all aspects of aggression. In all likelihood, it causes intense internal suffering to those who harbor it. It seems to make sense that this cognitive component of aggression, which is likely a driver but might also be a residual of anger and active - physical or verbal - aggression, is modifiable by managing emotions that uses cognition, intelligence and knowledge to regulate one's own and others' emotions and operates via cognitive mechanism of appraisal (the way

Table 9 Results of moderated mediation of grandiose narcissism via neuroticism on hostility

\begin{tabular}{lccc}
\hline Moderated Mediation Results & Coefficient & LLCI & ULCI \\
\hline Outcome: Neuroticism $\mathrm{R}^{2}=.31$, & $F(9,395)=19.71, p<.001$ & \\
NPI & $-.20^{* *}$ & -.29 & -.12 \\
Gender & $-.65^{* *}$ & -.85 & -.45 \\
NPI x Gender & -.07 & -.24 & .10 \\
Conditional effects: & & & \\
Among women & $-.17^{* *}$ & -.28 & -.06 \\
Among men & $-.24^{* *}$ & -.37 & -.12 \\
Outcome: Hostility $\mathrm{R}^{2}=.33, F(10,394)=19.41, p<.001$ & \\
NPI & .37 & -.16 & .90 \\
Gender & .34 & -.93 & 1.61 \\
NPI x Gender & $-1.18^{*}$ & -2.22 & -.15 \\
Neuroticism & $1.79^{* *}$ & 1.18 & 2.39 \\
Direct effects & & & \\
Among women & $.92^{*}$ & .21 & 1.62 \\
Among men & -.27 & -1.05 & .51 \\
Indirect effect via Neuroticism & & & \\
Among women & $-.30^{* *}$ & -.56 & -.09 \\
Among men & $-.43^{* *}$ & -.79 & -.15 \\
\hline
\end{tabular}

This analysis controlled for vulnerable narcissism and its interaction with gender, and dummy-coded site-of-collection differences. LLCI: Lower Limit Confidence Interval, ULCI: Upper Limit Confidence Interval. ${ }^{*} p<.05,{ }^{* *} p<.01$ people evaluate emotional situations) and situation modification (the way people identify responses to influence these situations; Lopes et al. 2011). Managing emotions, also known as the strategic emotion regulation ability, is described as antecedent-focused which means that it is an ability to effectively regulate emotions before an individual becomes fully aroused and it operates on antecedents of this arousal such as hostile cognition. It does not help people to manage conflict with others by amplifying positive affect and dampening negative affect in oneself. It also does not help control behavior or emotional expression in the midst of an intense emotional reaction. Instead, it represents a more strategic or intellectualized dimension of EI, involving the capacity to evaluate emotional situations and identify effective strategies for managing them. Our findings seem to confirm the clinical view that it is deficient strategies to maintain a positive selfimage and, in particular, defective self-regulation that contributes to the problematic self and affect states in narcissism (Pincus and Lukowitsky 2010).

Furthermore, our results add to the accumulating body of evidence showing that narcissism might qualitatively differ between men and women, with men displaying increased sensitivity to potentially threatening situations and maladaptive affective regulation and generally more emotionally dysfunctional characteristics (Jauk et al. 2017a, b; Morf and Rhodewalt 2001). Differences in brain activity and affective dysregulation, including general elevations in cortisol levels and exaggerated physiological stress responses were apparent only in narcissistic men, but not in women (Edelstein et al. 2010; Jauk et al. 2017a, b; Reinhard et al. 2012).

Our study revealed that grandiose narcissism's associations with the internal aspects of aggression are more complex than those of vulnerable narcissism with anger and hostility. First, we found that grandiose narcissism is generally unrelated to aggression outcomes. However, when we controlled for neuroticism in the models, the positive relation between grandiose narcissism and both anger and hostility increased, suggesting a suppression effect. Although, as mentioned earlier, our data do not allow for causal inferences, we speculate that emotional stability (low neuroticism) "protects" grandiose narcissistic individuals against experiencing increased levels of anger and hostility. Furthermore, it is noteworthy that in almost all 
our analyses where we looked into indirect effects of narcissism of each form on anger and hostility, results showed that direct effects remained positive and significant (the single exception being the conditional direct effect of grandiose narcissism on hostility among men). This in itself suggests that there is another factor which likely underlies the aggressive responses of narcissists, unrelated to neuroticism or EI. It might likely be common to both forms of narcissism. Indeed, recent findings suggest that this underlying factor might be a part of the "common core of narcissism", namely antagonism (Vize et al. 2019). Our results seem to support this possibility. The inconsistency between findings of Krizan and Johar (2015) and Vize et al. (2019) might only be ostensible as there seems to be space (and unexplained variance) for multiple factors driving aggression in narcissism, with some being more (such as neuroticism and managing emotions) and others less specific (such as antagonism) to particular forms of narcissism,.

Moreover, interesting and unexpected findings were related to the higher levels of anger and hostility among women than men. When trying to explain the former finding, we tested and found similar gender differences in another dataset from a published research using a Polish sample $(N=304 ; 193$ women; Czarna et al. 2016a, b; dataset from Study 1): women reported slightly (not significantly) higher levels of hostility and significantly higher levels of anger than men. Thus, it is possible that these gender differences in levels of internal aspects of aggression in Polish samples are not a chance finding. Since there is evidence that gender role identification and cultural norms contribute to gender differences in aggression (e.g. Milovchevich et al. 2001), future cross-cultural research might provide an explanation of these results.

Finally, our test inspired by the statistical procedure used by Jauk et al. $(2017 \mathrm{a}, \mathrm{b})$ confirmed that removing the variance related to neuroticism from the indices of vulnerable and grandiose narcissism significantly increased the correlation between the two forms, thus bringing us closer to the "core of narcissism". This finding is yet another piece of evidence suggesting that the two forms of narcissism are likely just different expressions of one underlying phenomenon masked by divergent levels of other traits, such as neuroticism, extraversion, approach-avoidance motivation.

Our research is not free from limitations. Above all, its correlational and cross-sectional nature does not allow to draw strong conclusions about causality (and mediation). A large part of interpretations of our results therefore remain speculative. As we cannot rule out alternative mechanisms and pathways or third variable effects, we cautiously formulate our conclusion that it is the common variance that vulnerable (and grandiose) narcissism shares with neuroticism or emotion managing that is responsible for anger and hostility without assuming strong causal links between the constructs. Future research would do well by experimentally testing whether interventions (such as psychotherapy, counseling, or training) aimed at improving managing emotions, emotion regulation, could help decrease hostility in vulnerable narcissism. Additionally, it would be worth to examine the relations between both forms of narcissism and anger/hostility as well as the neuroticism and emotion regulation ability from recently proposed theoretical frameworks, i.e. the Spectrum Model of Narcissism (Krizan and Herlache 2018) and the Trifurcated Model of Narcissism (Miller et al. 2016). Both models postulate entitlement and antagonism, respectively, as a common core for grandiose and vulnerable narcissism. Additionally, the authors of these models argue that both entitlement and antagonism might be responsible for aggression-related phenomena, such as anger, or aggressive behavior (Krizan and Herlache 2018; Miller et al. 2016; Vize et al. 2019). Finally, while our study design and instruments are strictly traitfocused and may not contribute much to the exciting new literature which examines narcissistic grandiosity and vulnerability as fluctuating states arising from a common core, an entire avenue for future research could be to investigate the interplay of dispositions and dynamic mechanisms linking situational cues and their interpretations with narcissistic states and aggressive responses.

\section{Conclusion}

In the current study we found that trait vulnerable narcissism, but not grandiose narcissism, was associated with a higher tendency toward anger and hostility. Neuroticism accounted for a large part of the relationship between vulnerable narcissism and anger/hostility, whereas it masked the links of grandiose narcissism with anger and hostility. Poor managing emotions, known also as strategic emotion regulation ability, also played a role in explaining the relationship between vulnerable narcissism and anger/hostility exclusively among men. These factors, however, were not capable of explaining the full association between narcissism and aggression. There were significant relationships between both forms of narcissism with aggression, remaining after neuroticism and emotion regulation were accounted for. These suggest that there is another underlying source of this link, which could be antagonism. Finally, we found that controlling for interindividual differences in neuroticism significantly increased the relationship between vulnerable and grandiose narcissism, bringing us closer to the common core of narcissism.

Funding Information This work was supported from a grant no 2015/19/ $\mathrm{B} / \mathrm{HS} 6 / 02214$ awarded to the first author and grant no 016/23/B/HS6/ 00312 awarded to the second author funded by National Science Centre in Poland.

Data Availability The datasets generated and analysed during the current study are available in the Open Science Framework repository, https:// mfr.osf.io/render?url=https $\% 3 \mathrm{~A} \% 2 \mathrm{~F} \% 2 \mathrm{Fosf}$.io $\% 2 \mathrm{~F} 946 \mathrm{vz} \% 2 \mathrm{Fdownload}$ 


\section{Compliance with Ethical Standards}

Human Participants and Animal Studies All procedures performed in studies involving human participants were in accordance with the ethical standards of the institutional research committee and with the 1964 Helsinki declaration and its later amendments or comparable ethical standards. This article does not contain any studies with animals performed by any of the authors.

Conflict of Interest The authors declare that the research was conducted in the absence of any commercial or financial relationships that could be construed as a potential conflict of interest.

Informed Consent Informed consent was obtained from all individual participants included in the study.

Open Access This article is distributed under the terms of the Creative Commons Attribution 4.0 International License (http:// creativecommons.org/licenses/by/4.0/), which permits unrestricted use, distribution, and reproduction in any medium, provided you give appropriate credit to the original author(s) and the source, provide a link to the Creative Commons license, and indicate if changes were made.

\section{References}

Ackerman, R. A., Donnellan, M. B., \& Wright, A. G. (2019). Current conceptualizations of narcissism. Current Opinion in Psychiatry, 32(1), 32-37.

Alexander, F. (1938). Remarks about the relation of inferiority feelings to guilt feelings. International Journal of Psychoanalysis, 19, 41-49.

Anderson, C. A., \& Bushman, B. J. (2002). Human aggression. Annual Review of Psychology, 53, 27-51.

Austin, E. J., Saklofske, D. H., Smith, M., \& Tohver, G. (2014). Associations of the managing the emotions of others (MEOS) scale with personality, the dark triad and trait EI. Journal of Personality and Individual Differences, 65, 8-13.

Bazińska, R., \& Drat-Ruszczak, K. (2000). The structure of narcissism measured with Polish adaptation of Raskin and Hall NPI. Czasopismo Psychologiczne, 6, 171-187.

Bettencourt, B., \& Miller, N. (1996). Gender differences in aggression as a function of provocation: A meta-analysis. Psychological Bulletin, $119(3), 422-447$.

Bettencourt, B., Talley, A., Benjamin, A. J., \& Valentine, J. (2006). Personality and aggressive behavior under provoking and neutral conditions: A meta-analytic review. Psychological Bulletin, 132(5), 751-777.

Binti Amad, S. (2015). Self-esteem and aggression: the relationships between explicit-implicit self-esteem, narcissism, and reactiveproactive aggression (doctoral dissertation). Cardiff, United Kingdom: Cardiff University.

Brackett, M. A., \& Mayer, J. D. (2003). Convergent, discriminant, and incremental validity of competing measures of emotional intelligence. Personality and Social Psychology Bulletin, 29(9), 11471158.

Brackett, M. A., Mayer, J. D., \& Warner, R. M. (2004). Emotional intelligence and its relation to everyday behaviour. Personality and Individual Differences, 36(6), 1387-1402.

Brackett, M. A., Rivers, S. E., Shiffman, S., Lerner, N., \& Salovey, P. (2006). Relating emotional abilities to social functioning: A comparison of self-report and performance measures of emotional intelligence. Journal of Personality and Social Psychology, 91, 780-795.

Bushman, B. J., \& Baumeister, R. F. (1998). Threatened egotism, narcissism, self-esteem, and direct and displaced aggression: Does selflove or self-hate lead to violence? Journal of Personality and Social Psychology, 75(1), 219-229.

Buss, A. H., \& Perry, M. (1992). The aggression questionnaire. Journal of Personality and Social Psychology, 63(3), 452-459.

Cain, N. M., Pincus, A. L., \& Ansell, E. B. (2008). Narcissism at the crossroads: Phenotypic description of pathological narcissism across clinical theory, social/personality psychology, and psychiatric diagnosis. Clinical Psychology Review, 28, 638-656.

Campbell, W. K., \& Miller, J. D. (Eds.). (2011). The handbook of narcissism and narcissistic personality disorder: Theoretical approaches, empirical findings, and treatments. Hoboken, NJ: John Wiley \& Sons Inc..

Caspi, A., Elder, G. H., \& Bem, D. J. (1987). Moving against the world: Life-course-patterns of explosive children. Developmental Psychology, 23(2), 308-313.

Costa, P. T., \& McCrae, R. R. (1992). Revised NEO-personality inventory (NEO-PI-R) and NEO five-factor inventory (NEO-FFI) manual. Odessa, FL: Psychological Assessment Resources.

Czarna, A. Z., Dufner, M., \& Clifton, A. D. (2014). The effects of vulnerable and grandiose narcissism on liking-based and dislikingbased centrality in social networks. Journal of Research in Personality, 50, 42-45.

Czarna, A. Z., Jonason, P. K., Dufner, M., \& Kossowska, M. (2016a). The dirty dozen scale: Validation of a Polish version and extension of the nomological net. Frontiers in Psychology, 6(0045). https://doi.org/ 10.3389/fpsyg.2016.00445.

Czarna, A. Z., Leifeld, P., Śmieja, M., Dufner, M., \& Salovey, P. (2016b). Do narcissism and emotional intelligence win us friends? Modeling dynamics of peer popularity using inferential network analysis. Personality and Social Psychology Bulletin, 42, 1588-1599.

Czarna, A. Z., Zajenkowski, M., \& Dufner, M. (2018). How does it feel to be a narcissist? Narcissism and emotions. In A. Hermann, A. Brunell, \& J. Foster (Eds.), The handbook of trait narcissism: Key advances, research methods, and controversies. Cham Switzerland: Springer.

Denson, T. F. (2013). The multiple systems model of angry rumination. Personality and Social Psychology Review, 17(2), 103-123.

Denson, T. F., Pedersen, W. C., Friese, M., Hahm, A., \& Roberts, L. (2011). Understanding impulsive aggression: Angry rumination and reduced self-control capacity are mechanisms underlying the provocation-aggression relationship. Personality and Social Psychology Bulletin, 37(6), 850-862.

Dickinson, K. A., \& Pincus, A. L. (2003). Interpersonal analysis of grandiose and vulnerable narcissism. Journal of Personality Disorders, 17(3), 188-207.

Edelstein, R. S., Yim, I. S., \& Quas, J. A. (2010). Narcissism predicts heightened cortisol reactivity to a psychosocial stressor in men. Journal of Research in Personality, 44(5), 565-572.

Edershile, E. A., \& Wright, A. G. (2019). Grandiose and vulnerable narcissistic states in interpersonal situations. Self and Identity, 1-17.

Emmons, R. A. (1987). Narcissism: Theory and measurement. Journal of Personality and Social Psychology, 52(1), 11-17.

Freud, S. (1932). Leonardo da Vinci and a memory of his childhood. In J. Strachey (Ed., trans.), The standard edition of the complete psychological works of Sigmund Freud (Vol.11, pp. 59-137). London, England: Hogarth press.

García-Sancho, E., Dhont, K., Salguero, J. M., \& Fernández-Berrocal, P. (2017). The personality basis of aggression: The mediating role of anger and the moderating role of emotional intelligence. Scandinavian Journal of Psychology, 58(4), 333-340. 
García-Sancho, E., Salguero, J. M., \& Fernández-Berrocal, P. (2014). Relationship between emotional intelligence and aggression: A systematic review. Aggression and Violent Behavior, 19(5), 584-591.

Goldberg, L. R. (1992). The development of markers of Big-Five factor structure. Psychological Assessment, 4(1), 26-42.

Goldenberg, I., Matheson, K., \& Mantler, J. (2006). The assessment of emotional intelligence: A comparison of performance-based and self-report methodologies. Journal of Personality Assessment, 86, 33-45.

Goryńska, E., Winiewski, M., \& Zajenkowski, M. (2015). Situational factors and personality traits as determinants of college students' mood. Personality and Individual Differences, 77, 1-6.

Gosling, S. D., Rentfrow, P. J., \& Swann, W. B. (2003). A very brief measure of the Big-Five personality domains. Journal of Research in Personality, 37, 504-528.

Grijalva, E., Newman, D. A., Tay, L., Donnellan, M. B., Harms, P. D., Robins, R. W., \& Yan, T. (2015). Gender differences in narcissism: A meta-analytic review. Psychological Bulletin, 141(2), 261-310.

Harrod, N. R., \& Scheer, S. D. (2005). An exploration of adolescent emotional intelligence in relation to demographic characteristics. Adolescence, 40(159), 503-512.

Hartung, C. M., \& Widiger, T. A. (1998). Gender differences in the diagnosis of mental disorders: Conclusions and controversies of the DSM-IV. Psychological Bulletin, 123(3), 260-278.

Hendin, H. M., \& Cheek, J. M. (1997). Assessing hypersensitive narcissism: A reexamination of Murray's narcissism scale. Journal of Research in Personality, 31(4), 588-599.

Hennig, J., Reuter, M., Netter, P., Burk, C., \& Landt, O. (2005). Two types of aggression are differentially related to serotonergic activity and the A779C TPH polymorphism. Behavioral Neuroscience, $119(1), 16-25$.

Jacobson, E. (1964). The self and the object world. New York, NY: International Universities Press.

Jauk, E., Benedek, M., Koschutnig, K., Kedia, G., \& Neubauer, A. C. (2017a). Self-viewing is associated with negative affect rather than reward in highly narcissistic men: An fMRI study. Scientific Reports, 7(1), 5804.

Jauk, E., Freudenthaler, H. H., \& Neubauer, A. C. (2016a). The dark triad and trait versus ability emotional intelligence. Emotional darkness differs between women and men. Journal of Individual Differences, $7,112-118$

Jauk, E., Neubauer, A. C., Mairunteregger, T., Pemp, S., Sieber, K., \& Rauthmann, J. F. (2016b). How alluring are dark personalities? The dark triad and attractiveness in speed dating. European Journal of Personality, 30(2), 125-138.

Jauk, E., Weigle, E., Lehmann, K., Benedek, M., \& Neubauer, A. C. (2017b). The relationship between grandiose and vulnerable (hypersensitive) narcissism. Frontiers in Psychology, 8, 1600.

Jaušovec, N., \& Jaušovec, K. (2005). Sex differences in brain activity related to general and emotional intelligence. Brain and Cognition, 59(3), 277-286.

Kaufman, S. B., Weiss, B., Miller, J. D., \& Campbell, W. K. (2018). Clinical correlates of vulnerable and grandiose narcissism: A personality perspective. Journal of Personality Disorders, 1-S10.

Konrath, S., Corneille, O., Bushman, B. J., \& Luminet, O. (2014). The relationship between narcissistic exploitativeness, dispositional empathy, and emotion recognition abilities. Journal of Nonverbal Behavior, 38(1), 129-143.

Krizan, K., \& Herlache, A. D. (2018). The Narcissism Spectrum model: A synthetic view of narcissistic personality. Personality and Social Psychology Review, 22, 3-31.

Krizan, Z., \& Johar, O. (2015). Narcissistic rage revisited. Journal of Personality and Social Psychology, 108, 784-801.

Lemerise, E. A., \& Arsenio, W. F. (2000). An integrated model of emotion processes and cognition in social information processing. Child Development, 71(1), 107-118.
Lopes, P. N., Nezlek, J. B., Extremera, N., Hertel, J., Fernández-Berrocal, P., Schütz, A., \& Salovey, P. (2011). Emotion regulation and the quality of social interaction: Does the ability to evaluate emotional situations and identify effective responses matter? Journal of Personality, 79(2), 429-467.

Maciantowicz, O., \& Zajenkowski, M. (2018). Is narcissistic anger fueled by neuroticism? The relationship between grandiose and vulnerable narcissism, neuroticism, and trait anger. Current Psychology. https:// doi.org/10.1007/s12144-018-9866-y.

Mandell, B., \& Pherwani, S. (2003). Relationship between emotional intelligence and transformational leadership style: A gender comparison. Journal of Business and Psychology, 17(3), 387-404.

Martinez, M. A., Zeichner, A., Reidy, D. E., \& Miller, J. D. (2008). Narcissism and displaced aggression: Effects of positive, negative, and delayed feedback. Personality and Individual Differences, 44(1), 140-149.

Martin, R., Watson, D., \& Wan, C. K. (2000). A three-factor model of trait anger: Dimensions of affect, behavior, and cognition. Journal of Personality, 68, 869-897.

Matthews, G., Deary, I. J., \& Whiteman, M. C. (2009). Personality traits (3rd ed.). Cambridge, England: Cambridge University Press.

Mayer, J. D., Caruso, D. R., \& Salovey, P. (1999). Emotional intelligence meets traditional standards for an intelligence. Intelligence, 27(4), 267-298.

Mayer, J. D., Caruso, D. R., Salovey, P., \& Sitarenios, G. (2003). Measuring emotional intelligence with the MSCEIT V2. 0. Emotion, 3(1), 97-105.

Mayer, J. D., \& Geher, G. (1996). Emotional intelligence and the identification of emotion. Intelligence, 22, 89-113.

Mayer, J. D., \& Salovey, P. (1997). What is emotional intelligence? In P. Salovey \& D. Sluyter (Eds.), Emotional development and emotional intelligence: Educational implications. New York, NY: Basic Books.

Mayer, J. D., Salovey, P., \& Caruso, D. R. (2004). Emotional intelligence: Theory, findings, and implications. Psychological Inquiry, 15, $197-$ 215.

Miller, J. D., Dir, A., Gentile, B., Wilson, L., Pryor, L. R., \& Campbell, W. K. (2010). Searching for a vulnerable dark triad: Comparing factor 2 psychopathy, vulnerable narcissism, and borderline personality disorder. Journal of Personality, 78(5), 1529-1564.

Miller, J. D., Hoffman, B. J., Gaughan, E. T., Gentile, B., Maples, J., \& Campbell, W. K. (2011). Grandiose and vulnerable narcissism: A nomological network analysis. Journal of Personality, 79, 10131042.

Miller, J. D., Lynam, D. R., Hyatt, C. S., \& Campbell, W. K. (2017). Controversies in narcissism. Annual Review of Clinical Psychology, 13, 291-315.

Miller, J. D., Lynam, D. R., McCain, J. L., Few, L. R., Crego, C., Widiger, T. A., et al. (2016). Thinking structurally about narcissism: An examination of the Five-Factor Narcissism Inventory and its components. Journal of Personality Disorders, 30, 1-18.

Miller, J. D., Lynam, D. R., Vize, C., Crowe, M., Sleep, C., MaplesKeller, J. L., et al. (2018). Vulnerable narcissism is (mostly) a disorder of neuroticism. Journal of Personality, 86(2), 186-199.

Milovchevich, D., Howells, K., Drew, N., \& Day, A. (2001). Sex and gender role differences in anger: An Australian community study. Personality and Individual Differences, 31(2), 117-127.

Morf, C., \& Rhodewalt, F. (2001). Unraveling the paradoxes of narcissism. A dynamic self- regulatory processing model. Psychological Injury, 12(4), 177-196.

Okada, R. (2010). The relationship between vulnerable narcissism and aggression in Japanese undergraduate students. Personality and Individual Differences, 49(2), 113-118.

Paulhus, D. L., \& John, O. P. (1998). Egoistic and moralistic bias in selfperceptions: The interplay of self-deceptive styles with basic traits and motives. Journal of Personality, 66(6), 1024-1060. 
Paulhus, D. L., \& Williams, K. M. (2002). The dark triad of personality: Narcissism, Machiavellianism, and psychopathy. Journal of Research in Personality, 36, 556-563.

Petrides, K. V., \& Furnham, A. (2000). Gender differences in measured and self-estimated trait emotional intelligence. Sex Roles, 42(5-6), 449-461.

Petrides, K. V., Vernon, P. A., Schermer, J. A., \& Veselka, L. (2011). Trait emotional intelligence and the dark triad traits of personality. Twin Research and Human Genetics, 14(1), 35-41.

Pincus, A. L., \& Lukowitsky, M. R. (2010). Pathological narcissism and narcissistic personality disorder. Annual Review of Clinical Psychology, 6, 421-446.

Pincus, A. L., Ansell, E. B., Pimentel, C. A., Cain, N. M., Wright, A., \& Levy, K. N. (2009). Initial construction and validation of the Pathological Narcissism Inventory. Psychological Assessment, 21, 365-379.

Raskin, R. N., \& Hall, C. S. (1979). A narcissistic personality inventory. Psychological Reports, 45, 590.

Reidy, D. E., Zeichner, A., Foster, J. D., \& Martinez, M. A. (2008). Effects of narcissistic entitlement and exploitativeness on human physical aggression. Personality and Individual Differences, 44(4), 865-875.

Reinhard, D. A., Konrath, S. H., Lopez, W. D., \& Cameron, H. G. (2012). Expensive egos: Narcissistic males have higher cortisol. PLoS One, 7(1), e30858

Rice, F. P. (1999). The adolescent: Development, relationships and culture (9th ed.). Boston, MA: Allyn \& Bacon.

Rogoza, R., Żemojtel-Piotrowska, M., Kwiatkowska, M. M., \& Kwiatkowska, K. (2018). The bright, the dark, and the blue face of narcissism: The Spectrum of narcissism in its relations to the metatraits of personality, self-esteem, and the nomological network of shyness, loneliness, and empathy. Frontiers in Psychology, 9, 343.

Rubin, M. M. (1999). Emotional intelligence and its role in mitigating aggression: A correlational study of the relationship between emotional intelligence and aggression in urban adolescents. Immaculata College, Immaculata, Pennsylvania: Unpublished Dissertation.

Rusch, N., Lieb, K., Gottler, I., Hermann, C., Schramm, E., Richter, H., et al. (2007). Shame and implicit self-concept in women with borderline personality disorder. American Journal of Psychiatry, 164, 500-508.

Ryan, K. M., Weikel, K., \& Sprechini, G. (2008). Gender differences in narcissism and courtship violence in dating couples. Sex Roles, $58(11-12), 802-813$.

Salovey, P., \& Mayer, J. D. (1990). Emotional intelligence. Imagination, Cognition and Personality, 9, 185-211.

Saul, L. J. (1947). Emotional maturity. Philadelphia: Lippincott.

Schmitt, D. P., Realo, A., Voracek, M., \& Allik, J. (2008). Why can't a man be more like a woman? Sex differences in Big Five personality traits across 55 cultures. Journal of Personality and Social Psychology, 94(1), 168-182.

Schönbrodt, F. D., \& Perugini, M. (2013). At what sample size do correlations stabilize? Journal of Research in Personality, 47(5), 609612.

Schutte, N. S., Malouff, J. M., Hall, L. E., Haggerty, D. J., Cooper, J. T., Golden, C. J., \& Domheim, L. (1998). Development and validation of a measure of emotional intelligence. Personality and Individual Differences, 25, 167-177.

Sedikides, C., Rudich, E. A., Gregg, A. P., Kumashiro, M., \& Rusbult, C. (2004). Are normal narcissists psychologically healthy? Self-esteem matters. Journal of Personality and Social Psychology, 87(3), 400416.
Sharpe, J. P., \& Desai, S. (2001). The revised neo personality inventory and the MMPI-2 psychopathology five in the prediction of aggression. Personality and Individual Differences, 31, 505-518.

Stinson, F. S., Dawson, D. A., Goldstein, R. B., Chou, S. P., Huang, B., Smith, S. M., et al. (2008). Prevalence, correlates, disability, and comorbidity of DSM-IV narcissistic personality disorder: Results from the wave 2 National Epidemiologic Survey on alcohol and related conditions. Journal of Clinical Psychiatry, 69, 1033-1045.

Strus, W., Cieciuch, J., \& Rowiński, T. (2014). Polska adaptacja kwestionariusza IPIP-BFM- 50 do pomiaru pięciu cech osobowości w ujęciu leksykalnym [Polish adaptation of IPIPBFM-50 measuring five personality traits in a lexical approach]. Roczniki Psychologiczne, 17, 327-346.

Śmieja, M., Orzechowski, J., \& Stolarski, M. S. (2014). TIE: An ability test of emotional intelligence. PLoS One, 9(7), e103484. https://doi. org/10.1371/journal.pone.010.

Twenge, J. M., \& Campbell, W. K. (2003). Isn't it fun to get the respect that we're going to deserve? Narcissism, social rejection, and aggression. Personality and Social Psychology Bulletin, 29(2), 261272.

Van Rooy, D. L., Alonso, A., \& Viswesvaran, C. (2005). Group differences in emotional intelligence scores: Theoretical and practical implications. Personality and Individual Differences, 38, 689-700.

Vize, C. E., Collison, K. L., Crowe, M. L., Campbell, W. K., Miller, J. D., \& Lynam, D. R. (2019). Using dominance analysis to decompose narcissism and its relation to aggression and externalizing outcomes. Assessment, 26(2), 260-270.

Vonk, J., Zeigler-Hill, V., Mayhew, P., \& Mercer, S. (2013). Mirror, mirror on the wall, which form of narcissist knows self and others best of all? Personality and Individual Differences, 54, 396-401.

Webster, G. D. (2006). Low self-esteem is related to aggression, but especially when controlling for gender: A replication and extension of Donnellan et al. (2005). Representative Research in Social Psychology, 29, 12-18.

Watson, D. (2000). Mood and temperament. New York, NY: Guilford.

Zajenkowski, M., Goryńska, E., \& Winiewski, M. (2012). Variability of the relationship between personality and mood. Personality and Individual Differences, 52, 858-861.

Zajenkowski, M., Maciantowicz, O., Szymaniak, K., \& Urban, P. (2018). Vulnerable and grandiose narcissism are differentially associated with ability and trait emotional intelligence. Frontiers in Psychology, 9, 1606.

Zajenkowski, M., Witowska, J., Maciantowicz, O., \& Malesza, M. (2016). Vulnerable past, grandiose present: The relationship between vulnerable and grandiose narcissism, time perspective and personality. Personality and Individual Differences, 98, 102-106.

Zeigler-Hill, V., \& Vonk, J. (2015). Dark personality features and emotion dysregulation. Journal of Social and Clinical Psychology, 34, 692 704.

Zhang, H., Wang, Z., You, X., Lu, W., \& Luo, Y. (2015a). Associations between narcissism and emotion regulation difficulties: Respiratory sinus arrhythmia reactivity as a moderator. Biological Psychology, $110,1-11$.

Zhang, W., Zou, H., Wang, M., \& Finy, M. S. (2015b). The role of the dark triad traits and two constructs of emotional intelligence on loneliness in adolescents. Personality and Individual Differences, $75,74-79$.

Publisher's Note Springer Nature remains neutral with regard to jurisdictional claims in published maps and institutional affiliations. 